\title{
CLINICOEPIDEMIOLOGICAL STUDY ON PAEDIATRIC ECZEMAS IN A TERTIARY CARE CENTRE
}

\author{
Dhanalakshmi Kasi ${ }^{1}$, Senthil Ganapathy², Vinothiney Krishna Moorthy33, Sindhuja Balaji ${ }^{4}$
}

1Associate Professor, Department of Dermatology, Thanjavur Medical College, Thanjavur, Tamilnadu, India. 2 Assistant Professor, Department of Dermatology, Thanjavur Medical College, Thanjavur, Tamilnadu, India. 3 Postgraduate Student, Department of Dermatology, Thanjavur Medical College, Thanjavur, Tamilnadu, India. ${ }^{4}$ Associate Professor, Department of Dermatology, Thanjavur Medical College, Thanjavur, Tamilnadu, India.

\section{ABSTRACT}

\section{BACKGROUND}

Paediatric eczemas are quite a common type of dermatosis that occur in children, who attend the dermatology outpatient department. They have been relatively few reports on paediatric eczema in the literature.

Aim- To study the epidemiological profile and clinical characteristics of paediatric eczemas.

\section{MATERIALS AND METHODS}

A prospective observational study was conducted for a period of one year in 50 children less than or equal to 18 years presenting with eczemas.

\section{RESULTS}

The study showed a male preponderance (54\%). The average age at presentation was 5-15 yrs. Insect bite allergy (30-23\%) was the predominant type in older children, whereas atopic eczema (5-14\%) was more prevalent among infants. Morphologically, acute type of eczema predominated in infants with eczema (5-14\%), while chronic eczema in older children (47-86\%). Face was involved in $42.85 \%$ of infants with eczema, while extensor surface (44.18\%) was more commonly affected in older children. Forty-three patients showed allergy to various materials like ornaments, dust, fabrics, footwear and cosmetics.

\section{CONCLUSION}

Paediatric eczemas are not extremely studied worldwide, except for atopic eczema. This study emphasises on the clinical and epidemiological profile of paediatric eczemas.

\section{KEY WORDS}

Eczemas, Paediatrics, Epidemiology.

HOW TO CITE THIS ARTICLE: Kasi D, Ganapathy S, Moorthy VK, et al. Clinicoepidemiological study on paediatric eczemas in a tertiary care centre. J. Evolution Med. Dent. Sci. 2018;7(46):5045-5048, DOI: 10.14260/jemds/2018/1122

\section{BACKGROUND}

Eczema is a chronic relapsing inflammatory skin disease characterised clinically by pruritus, erythema, scaly and clustered papulovesicles induced by various endogenous or exogenous factors. The exogenous eczemas include irritant contact dermatitis, allergic contact dermatitis, photoallergic contact dermatitis, eczematous polymorphic light eruptions etc. Whereas endogenous eczemas are of atopic dermatitis, seborrheic dermatitis, asteatotic eczema, discoid eczema, stasis eczema, hand eczema, juvenile plantar dermatoses etc.

Commonly encountered eczemas in paediatric practise, rare atopic dermatitis, pityriasis alba, juvenile plantar dermatoses in older children and seborrheic dermatitis and diaper dermatitis in infants. The study on paediatric eczemas are relatively less, except for atopic eczemas. Hence, in this study we analysed the epidemiological profile and clinical characteristics of paediatric eczemas in a tertiary care hospital.

'Financial or Other Competing Interest': None.

Submission 21-09-2018, Peer Review 24-10-2018,

Acceptance 31-10-2018, Published 12-11-2018.

Corresponding Author:

Dr. Senthil Ganapathy,

AA-23, Thangam Nagar,

M. C. Road, Thanjavur,

Tamilnadu, India.

E-mail: drsenthilganapathy@gmail.com

DOI: $10.14260 /$ jemds $/ 2018 / 1122$

\section{MATERIALS AND METHODS}

A single centre prospective and observational study was conducted for a period of one year. Fifty children with eczemas of age less than or equal to 18 were selected for the study after Ethical Committee approval. A written informed consent in the language known to them was obtained from the parents/guardian for including into the study and capturing photographs. All paediatric patients with eczemas equal to or less than 18 years were included in the study. Terminally ill patients and patients with exanthematous fever were excluded from the study.

A detailed history was taken with the help of a designed proforma, which included information on age, gender, personal history, family history of atopy, clinical features, onset with duration, extent of involvement, previous treatment details, associated comorbid illnesses, birth history and immunisation history. A thorough clinical examination was done and arrived at definitive clinical diagnosis. Relevant investigations were done. After analysing the history, clinical examination and relevant investigation, type of eczema and its stage were ascertained. The data was tabulated, analysed and compared with data of other studies. The primary objective of the study was to study the prevalence of paediatric eczemas in a tertiary care setting. Secondary objectives were to type and stage the eczemas according to the clinical presentation.

Statistical analyses of the data were performed using SPSS version STAT 8.0. Microsoft Word and Excel have been used to generate graphs, tables etc. Data collected was analysed using Chi-square test showed no significant relation between 
distribution of lesion and age group, whereas it showed significant relation between allergies and gender. The sample size was estimated by consulting Biostatistician. The sample size of 50 was enough to maintain the power of study to at least $80 \%$.

\section{RESULTS}

The overall incidence of eczema in children was about 50 (11.68\%). Male children accounted for 27 (54\%) of the study sample and female children accounted for $23(46 \%)$ of it. The average age at presentation was 9.55 years (SD) with a median of 10 years (range 5-15 years). Among these 50 children, 7 were infants and 43 were between 1 year and 18 years.

Among infants, $5(10 \%)$ were male children and 2 (4\%) were female children with a male-female ratio of $2.5: 1$. The average age at onset was 8 (SD) with a median of 10 months. The distribution of patients based on age is given in Table 1. A family history of atopy was noted in 3 patients (42.85\%). All the infants who were exclusively breastfed for a period of six months were 6 . All were fully immunised till age.

The childhood group from 1-18 years had 43 patients, which included 22 male children and 21 female children with a male-female ratio of 1.04: 1 . The distribution was as follows: - 1 -5 years (18\%); 6-10 years (22\%); $11-14$ years $(18 \%)$; 15 18 years (28\%). The common age group affected was $15-18$ years. The mean age of the disease was 11 years (SD) with a median of 11 years. The age and sex distribution are given in Table 1. Among 43 patients, 16 had not fully immunised. They missed their 10 and 16 years. TT immunisation, especially patients of 15-18 years.

The distribution of various clinical patterns of eczema in this study group is given in Table 2 . In infants, 4 had atopic eczema (57.14\%), 2 had insect bite allergy (28.57\%) and one had diaper dermatitis (14.28\%). In childhood group insect bite allergy was seen in 11 patients (25.58\%), contact dermatitis in 8 patients (18.60\%), atopic eczema in 3 patients (6.97\%), seborrheic dermatitis in 5 patients $(11.62 \%)$, hand and foot eczema in 5 patients $(11.62 \%)$, sweat retention dermatitis in 3 patients (6.97\%), photoallergic dermatitis in 2 patients (4.65\%) and others (13.95\%) including 2 cases of infective eczematoid dermatitis and one case on each of nummular eczema, discoid eczema, eczematous polymorphic light eruptions and chronic eczema. Itching was the presenting complaint of most of the patients (84\%).

In infants, acute type of eczema was more common (57.14\%) than subacute $(28.57 \%)$ and chronic eczema (14.28\%). In childhood, chronic eczema (41.86\%) was more common than acute (37.20\%) and subacute $(20.93 \%)$. These details were given in Table 5 .

The common sites of involvement were face, hands and leg. In infants, face involvements $(42.85 \%)$ is more followed by flexor $(28.57 \%)$, extensor (14.28\%) and both flexor and extensor (14.28\%). In older children extensor (44.18\%) surface is more common than flexor $(23.25 \%)$, face $(16.27 \%)$, scalp (4.65\%) and both flexor and extensor (11.62\%). The distribution of the lesions were showed in Table 3. Table 3 by Chi-square analysis shows that null hypothesis is accepted because the calculated (6.02) value is less than table (9.488) value. Hence, there is no relationship between age group of children and distribution of eczema.
Forty-three patients showed allergy to various things including ornaments $(32.55 \%)$, dust $(20.96 \%)$, fabrics and footwear (23.25\%), cosmetics (13.91\%) and others $(9.30 \%)$ The distribution was shown in Table 4. Fourteen patients had allergy to ornaments which includes nickel ( 9 patients), brass ( 2 patients), brass and nickel (1 patient), brass and silver (1 patient) and iron (1 patient). Ten patients had allergy to fabrics, i.e. cotton, silk, polyester and leather in the form of footwear and watches. Nine patients had dust allergy. Six patients had allergy for cosmetics, especially for fragrance mix, face cream, powder, shampoo, kumkum etc. Table 4 by Chisquare analysis shows that null hypothesis is rejected, because the calculated (17.55) value is more than table (9.488) value. Hence, there is relationship between gender and types of allergies.

Various associated disease observed in infants were bronchial asthma in 2 infants.

\begin{tabular}{|c|c|c|c|}
\hline Age Distribution & Male & Female & Total \\
\hline $0-1$ yr. & $5(10 \%)$ & $2(4 \%)$ & $7(14 \%)$ \\
\hline $1-5$ yrs. & $3(6 \%)$ & $6(12 \%)$ & $9(18 \%)$ \\
\hline $6-10$ yrs. & $4(8 \%)$ & $7(14 \%)$ & $11(22 \%)$ \\
\hline $11-14$ yrs. & $6(12 \%)$ & $3(6 \%)$ & $9(18 \%)$ \\
\hline $15-18$ yrs. & $9(18 \%)$ & $5(10 \%)$ & $14(28 \%)$ \\
\hline Total & $27(54 \%)$ & $23(46 \%)$ & $50(100 \%)$ \\
\hline \multicolumn{4}{|r|}{ Table 1. Age and Sex distribution of Patients } \\
\hline
\end{tabular}

\begin{tabular}{|c|c|c|c|c|}
\hline Aetiology & $\begin{array}{c}\text { No. of } \\
\text { Infants }\end{array}$ & $\mathbf{\%}$ & $\begin{array}{c}\text { No. of } \\
\text { Children }\end{array}$ & $\%$ \\
\hline Contact dermatitis & 1 & $14.28 \%$ & 8 & $18.60 \%$ \\
\hline Atopic eczema & 4 & $57.14 \%$ & 3 & $6.97 \%$ \\
\hline Hand foot eczema & 0 & $0 \%$ & 5 & $11.62 \%$ \\
\hline Insect bite allergy & 2 & $28.57 \%$ & 11 & $25.58 \%$ \\
\hline $\begin{array}{c}\text { Seborrheic } \\
\text { dermatitis }\end{array}$ & 0 & $0 \%$ & 5 & $11.62 \%$ \\
\hline $\begin{array}{c}\text { Sweat retention } \\
\text { dermatitis }\end{array}$ & 0 & $0 \%$ & 3 & $6.97 \%$ \\
\hline $\begin{array}{c}\text { Photo allergic } \\
\text { dermatitis }\end{array}$ & 0 & $0 \%$ & 2 & $4.65 \%$ \\
\hline Others & 0 & $0 \%$ & 6 & $13.95 \%$ \\
\hline \multicolumn{6}{|c|}{ Total } & 7 & 43 & \\
\hline $\begin{array}{c}\text { Table 2. Distribution of Clinical Patterns of Eczema in } \\
\text { Children }\end{array}$ \\
\hline
\end{tabular}

\begin{tabular}{|c|c|c|c|c|}
\hline Site & No. & \% & No. & \% \\
\hline Face & 3 & $42.85 \%$ & 7 & $16.27 \%$ \\
\hline Flexor & 2 & $28.57 \%$ & 10 & $23.25 \%$ \\
\hline Extensor & 1 & $14.28 \%$ & 19 & $44.18 \%$ \\
\hline Both & 1 & $14.28 \%$ & 5 & $11.62 \%$ \\
\hline Scalp & 0 & $0 \%$ & 2 & $4.65 \%$ \\
\hline Table 3. Clinical distribution of Eczema in Infants and in \\
Children \\
\hline
\end{tabular}

\begin{tabular}{|c|c|c|c|}
\hline Types of Allergens & Male & Female & Total \\
\hline Cosmetics & 5 & 1 & $6(13.91 \%)$ \\
\hline Dust & 5 & 4 & $9(20.96 \%)$ \\
\hline Fabrics, Footwear & 3 & 7 & $10(23.25 \%)$ \\
\hline Ornaments & 8 & 6 & $14(32.55 \%)$ \\
\hline Plants, Food & 2 & 2 & $4(9.30 \%)$ \\
\hline Total Table 4. Types of Allergies \\
\hline \multicolumn{4}{|c|}{} \\
\hline
\end{tabular}




\begin{tabular}{|c|c|c|}
\hline Types & Infantile & Childhood \\
\hline Acute & $4(57.14 \%)$ & $16(37.20 \%)$ \\
\hline Subacute & $2(28.57 \%)$ & $9(20.93 \%)$ \\
\hline Chronic & $1(14.28 \%)$ & $18(41.86 \%)$ \\
\hline \multicolumn{3}{|c|}{ Table 5. Stages of Eczema } \\
\hline
\end{tabular}

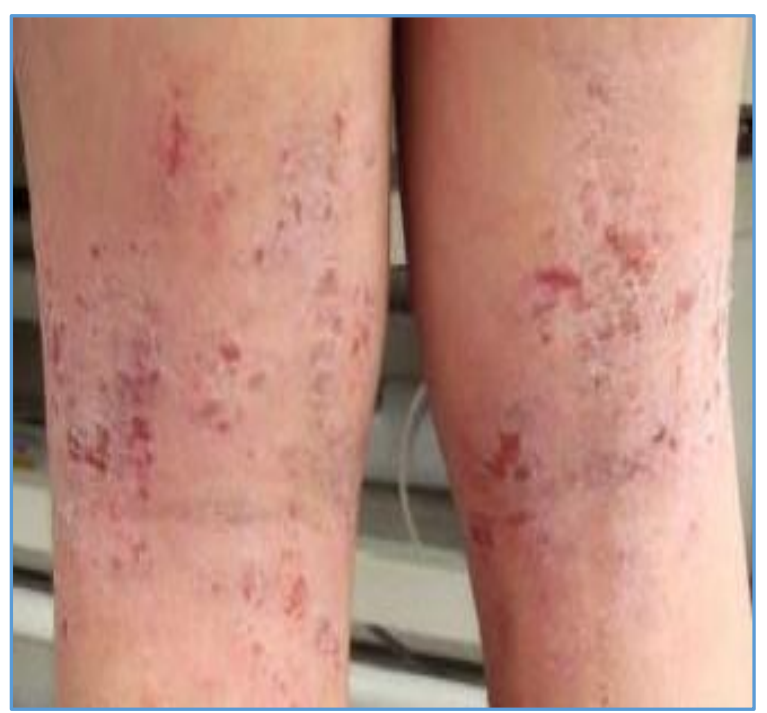

Figure (a). Atopic Dermatitis

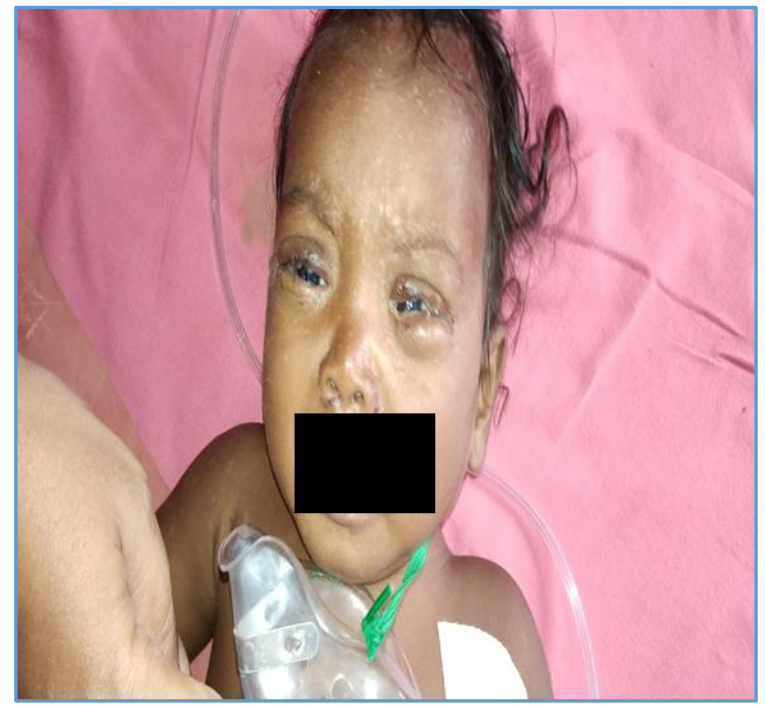

Figure (b). Seborrheic Dermatitis

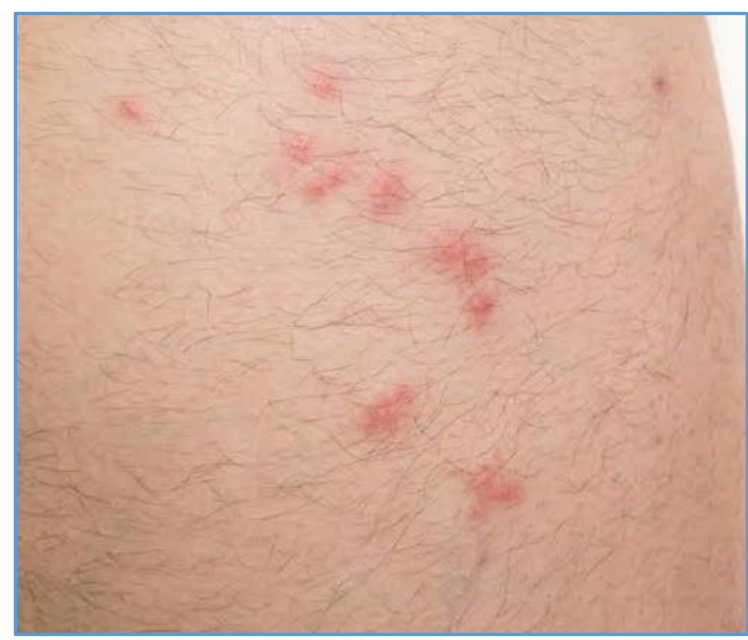

Figure (c). Insect Bite Allergy

\section{DISCUSSION}

Eczema is a reactive inflammatory group of disorders, which are triggered by both exogenous and endogenous causes. Paediatric eczemas of common occurrence are atopic dermatitis, infantile seborrheic dermatitis, diaper dermatitis, insect bite allergy, allergic contact dermatitis etc.

The average median age at presentation was 11 years (range 5-15 years) in our study, whereas a study of Sharma et al showed the age of median disease onset was 8 years (range 1-15 years).

Gender ratio varied greatly between the studies, though all have reported a male predominance, $(1,2,3,4)$ which was in par with our study (2.5: 1 for infants and 1.04: 1 for children).

The finding of Dhar and Kanwar showed that $52.7 \%$ had acute eczema, while $47.4 \%$ of childhood patients had chronic type of eczema. (2) Data from Indian study by Jain showed that in infants eczema was acute in $52.72 \%$, subacute in $23.35 \%$, chronic in $23.35 \%$ and follicular in $0.46 \%$ at the time of presentation, while in older children acute eczema was seen in $28.79 \%$, subacute in $23.38 \%$, chronic in $47.40 \%$ and follicular in $0.43 \%$.(5) In Dhar et al study acute eczema was most prevalent and was found in $42 \%$ patients followed by subacute in $41 \%$ and chronic eczema in $17 \%$.(6) In our study also acute type of eczema predominated in infants with eczema (57.14\%), while chronic eczema predominated in childhood eczema (47.86\%).

In an Indian study $79 \%$ in the infantile atopic dermatitis patients had facial involvement, $42 \%$ had flexors affected, $52.3 \%$ had extensor involvement and $5.7 \%$ had both flexors and extensors affected, while in childhood group the corresponding figures were $74.5 \%, 35.5 \%, 56.32 \%$ and $8.24 \%$ respectively. $(7,2)$ In the study by Dhar et al 39\%, 38\%, 20\% and $3 \%$ patients had flexor, extensor, face and both flexor and extensor involvement.(3) Our study also showed that in the infants with eczema had face involvement (42.85\%), flexor (28.57\%), extensor (14.28\%) and both flexor and extensor (14.28\%). In children extensor (44.18\%), flexor (23.25\%), face (16.27\%), scalp (4.65\%) and both flexor and extensor (11.62\%). Facial involvement is less in childhood eczema in our study.

Cradle cap was observed or history of such occurrence was present in $92.3 \%$ of patients, but no cases of cradle cap was seen in our study.(3) Most of the Indian studies show that atopic eczema was more common among infants and contact allergy was more common among childhood population. $(5,6,2,8)$ In our study atopic eczema (57.14\%) was more common in infants, but insect bite allergy was more common (25.58\%) among older children.

Allergens of particular importance in children include paraphenylenediamine, tosylamide, formaldehyde resin and nickel. $(9,10,11)$ Nickel sensitivity is derived from ear piercing, use of bracelets, necklaces, rings and metallic zipper containing nickel.(10) Nickel allergy ranked highest. The reported prevalence of nickel allergy was $0.7 \%$ and present or past allergic contact dermatitis $0.9-14.9 \%{ }^{(12)}$ In a previous Indian study on patients of all ages with hand-foot ACD, leather was found to be a most common allergen than rubber. (9) Our study also revealed that more people are allergic to nickel (32.55\%), leather (23.25\%) especially in the form of footwear, brass, cotton, etc. 


\section{Limitations of the Study}

The limitation of this study are small sample size, no proper epidemiological criteria for diagnosis, relationship with environmental factors and impact of eczemas on children not assessed.

\section{CONCLUSION}

Therefore, more studies with larger sample sizes are needed for better understanding of the paediatric dermatoses.

\section{REFERENCES}

[1] Sarkar R, Kanwar AJ. Clinico-epidemiological profile and factors affecting severity of atopic dermatitis in north Indian children. Indian J Dermatol 2004;49(3):117-22.

[2] Dhar S, Kanwar AJ. Epidemiology and clinical pattern of atopic dermatitis in North Indian pediatric population. Paediatric Dermatol 1998;15(5):347-51.

[3] Kaujalgi R, Handa S, Jain A, et al. Ocular abnormalities in atopic dermatitis in Indian patients. Indian J Dermatol Venereol Leprol 2009;75(2):148-51.

[4] Dhar S, Kanwar AJ. Personal and family history of atopy in children with atopic dermatitis in North India. Indian J Dermatol 1997;42(1):9-13.

[5] Jain N, Khandpur S. Paediatric dermatoses in India. Indian J Dermatol Venereol Leprol 2010;76(5):451-4.
[6] Dhar S, Mandal B, Ghosh A. Epidemiology and clinical pattern of atopic dermatitis in 100 children seen in city hospital. Indian J Dermatol 2002;47(4):202-4.

[7] Dhar S, Banerjee R. Atopic dermatitis in infants and children in India. Indian J Dermatol Venereol Leprol 2010;76(5):504-13.

[8] Kanwar AJ, De D. Epidemiology and clinical features of atopic dermatitis in India. Indian J Dermatol 2011;56(5):471-5.

[9] Sharma VK, Asati DP. Pediatric contact dermatitis. Indian J Dermatol Venereol Leprol 2010;76(5):514-20.

[10] Fowler F. Regional contact dermatitis. In: Rietscher RC, Fowler JF, eds. Fisher's contact dermatitis. $6^{\text {th }}$ edn. Hamilton: BC Decker Inc., 2008: p. 38-43.

[11] Mortz CG, Lauritsen JM, Bindslev-Jensen C, et al. Contact allergy and allergic contact dermatitis in adolescents: prevalence measures and associations. The Odense Adolescence Cohort Study on Atopic Diseases and Dermatitis (TOACS). Acta Derma Venereol 2002;82(5):352-8

[12] Park K. Preventive medicine in obstetrics, paediatrics and geriatrics. In: Park K, edr. Textbook of preventive and social medicine. 22nd edn. Jabalpur: Banarsidas Bhanot Publishers 2013: p. 359-411. 